\title{
A Clinical Trial
}

\section{Radiofrequency Denervation of the Lumbar Zygapophysial Joints: 10-Year Prospective Clinical Audit}

Michael Gofeld ${ }^{1}, \mathrm{MD}$, Jain Jitendra ${ }^{2}, \mathrm{MD}$, and Gil Faclier ${ }^{1}, \mathrm{MD}$

From: ${ }^{1}$ Pain Management Program, Department of Anesthesia,

Sunnybrook Health Science Centre, Toronto, Ontario, Canada and ${ }^{2}$ Spine and Pain

Clinic, Mumbai, India, Dr. Gofeld ${ }^{1}$ and Dr. Faclier ${ }^{1}$ are

Assistant Professors at the University of Toronto, Canada. Dr. Jitendra ${ }^{2}$ is practicing at the

Spine and Pain Clinic, Badra West, Mumbai, India, and SL Raheja Hospital

Mahim, Mumbai, India.

Address Correspondence: Michael Gofeld MD

2075 Bayview Avenue, Toronto, Ontario,

Canada M4N 3M5

E-mail:

michael.gofeld@sunnybrook.ca

Funding: Department of Anesthesia, Sunnybrook Health Sciences Centre

Conflict of Interest: None. Manuscript received: 08/23/2006 Revisions received: 10/02/2006

Accepted for publication: $11 / 08 / 2006$

Free Full manuscript: www.painphysicianjournal.com
Background: Evidence for the efficacy of zygapophysial joint nerve radiofrequency neurotomy has remained controversial. Two randomized controlled trials showed positive results, but two others demonstrated no benefit. One carefully performed prospective trial confirmed high efficacy and lasting pain relief after the procedure; however, selection criteria for this study were superfluous, which resulted in a small number of patients available for follow up.

Objectives: A large clinical audit with routine patient selection and use of appropriate technique was undertaken to determine the effect of radiofrequency neurotomy of the lumbar facet joints for relief of chronic low back pain.

Design: Prospective clinical audit for quality was conducted in the pain clinic affiliated with a tertiary care teaching hospital.

Setting: An interventional pain management setting in Canada.

Methods: All patients with low back pain of more than 6 months' duration, with or without non-radicular radiation to the buttock, hip, and leg were included.

From January 1991 to December 2000, eligible patients underwent standardized diagnostic work-up, which included a self-reported pain questionnaire, physical examination, review of imaging studies, and diagnostic blockades. Those with an appropriate response to comparative double diagnostic blocks underwent standardized radiofrequency denervation of the lumbar zygapophysial joints. Patients were asked to estimate total perceived pain reduction (on a scale from $0 \%$ to $100 \%$ ) at 6 weeks and at 6,12 , and 24 months after the procedure.

Results: Of the 209 patients, 174 completed the study, and 35 were lost to follow-up or did not provide complete data for assessment. Of the 174 patients with complete data, 55 $(31.6 \%)$ experienced no benefit from the procedure. One hundred and nineteen patients $(68.4 \%$ ) had good (> 50\%) to excellent (> 80\%) pain relief lasting from 6 to 24 months.

Conclusion: This large, prospective clinical audit indicates that proper patient selection and anatomically correct radiofrequency denervation of the lumbar zygapophysial joints provide long-term pain relief in a routine clinical setting.

Key words: low back pain, lumbar zygapophysial joint, radiofrequency denervation, clinical audit

Pain Physician 2007; 10:291-299 
T he prevalence of chronic pain due to degenerative changes or traumatic damage of the lumbar zygapophysial (facet) joints has been estimated to be as high as $45 \%$ of total chronic low back pain causes (range $15 \%$ to $45 \%$ ) $(1,2)$. Ghormley introduced the concept of lumbar facet syndrome in 1933 and claimed that the facet joints are responsible for lumbosacral pain following wear-and-tear trauma of the lumbar spine (3). Shealy developed a procedure for radiofrequency rhizotomy of the articular nerves, publishing the first description in 1975 (4). Despite the fact that the applied anatomy for this technique was subsequently disproved (5), radiofrequency denervation of the zygapophysial joints has become a frequently performed procedure for the treatment of chronic low back pain. Four randomized controlled studies have been published to date, 2 with positive results $(6,7)$, and 2 showing no benefit over a sham procedure $(8,9)$. However, none of these studies implemented the available knowledge of applied surgical anatomy of lumbar medial branches $(5,10)$. Retrospectively, it was concluded that the selection criteria and methodology of diagnostic blockade were also flawed (11).

Only Dreyfuss et al (12) conducted a prospective clinical trial based on strict selection criteria, comparative double diagnostic blocks, and anatomically accurate positioning of the electrode parallel to the target nerve. Although the follow-up cohort was small, that study yielded the best results ever reported. Frequently, however, the results of a clinical trial cannot be reproduced in other studies or in clinical practice. This external validity problem may arise if the characteristics of patients in the study cohort differ from those of the population with the disease. One method of confirming the results of a previous study and solving the problem of reproducibility is to conduct a clinical audit based on available data to ensure the knowledge is being used to best effect. Formally initiated in 1993 at the United Kingdom's National Health Service (NHS), clinical audit was defined as "a quality improvement process that seeks to improve patient care and outcomes through systematic review of care against explicit criteria and the implementation of change" (13). Practically, 1 or 2 specific parameters are followed up in order to answer 1 or 2 specific questions. A recently published clinical audit of the results of radiofrequency neurotomy for chronic neck pain provided evidence of efficacy and generalizability of the procedure in routine clinical practice (14). We have conducted a similar audit of studied influences of patient selection, diagnostic blocks, and radiofrequency procedures performed in the specific clinical setup on the major outcome parameter - overall perceived pain reduction. The aim of the present study was primarily quality control for the procedure in routine practice in a university hospital.

\section{Methods}

From January 1991 to December 2000, the results of radiofrequency neurotomy of lumbar zygapophysial joints were collected and saved in the university pain clinic database. Every patient with pain predominantly of the low back of more than 6 months' duration and with average pain score of more than 5 out of 10, with or without non-radicular radiation of the pain to the buttock, hip, and leg, was considered for single-blind comparative double diagnostic blocks. Patients also had to demonstrate an understanding of the principles of diagnostic blocks and the follow-up requirements.

Patients who exhibited a radicular pattern of pain, neurogenic claudication, and pain predominantly of the leg with or without neurological deficit were excluded. No patients in the study had undergone spinal surgery.

Patients with depression controlled by medication, neurological deficit unrelated to the major complaint, or radiological appearance of degenerative disk disease and spinal stenosis, as well as those involved in litigation related to the chronic pain or receiving worker's compensation benefits, were not excluded.

Before admission, each patient completed a psychological screening tool based on the combination of the Brief Pain Inventory and McGill Pain Questionnaire $(15,16)$. Those who reported multiple unrelated painful sites, expressed significant psychopathology, or had unrealistic goals were not accepted as candidates for interventional pain management.

\section{Technique}

Diagnostic blocks of the lumbar medial branches and the fifth lumbar (L5) and first sacral (S1) dorsal rami were performed. The segmental levels to be blocked were identified by the location of maximal tenderness and were correlated with radiological findings. Injections were performed at a minimum of 3 levels, either unilaterally or bilaterally, depending upon the patient's presentation. The most common levels for injection extended from L3-L4 to S1. The needle position for blockade of the medial branches 

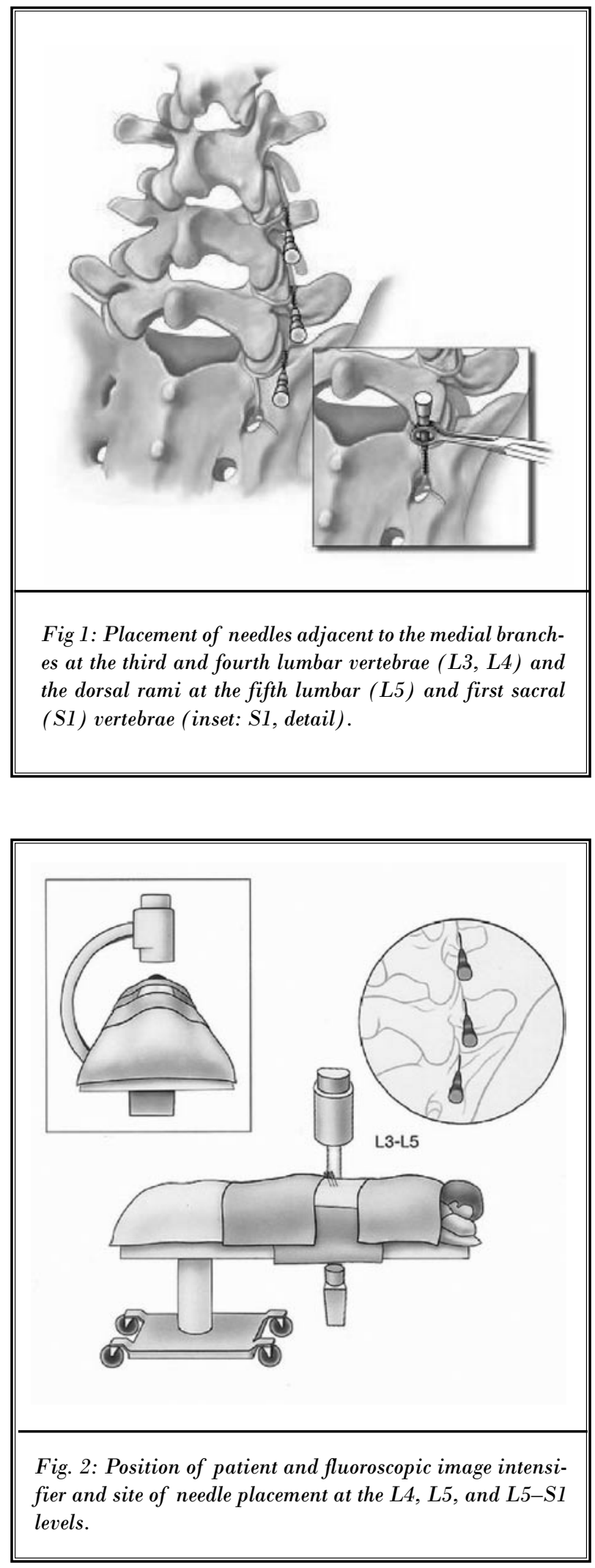

at $\mathrm{L} 3-\mathrm{L} 4$ and the dorsal rami at $\mathrm{L} 5$ and $\mathrm{S} 1$ are shown in Fig. 1.

All procedures were performed under fluoroscopy. The image intensifier was positioned as shown in Figs. 2 and 3 . The target was the junction of the transverse process with the base of the superior articular process (SAP). At the L5-S1 level, the target was the sacral ala at the base of the S1 SAP; at the S1 level, the target was the outer portion of the posterior $\mathrm{S} 1$ foramen at the 12 o'clock position. Care was taken to ensure that the needle did not pass into the sacral canal.

No sedation was used during the diagnostic procedure. Patients were blinded as to the agent used for diagnostic block. Skin anesthesia via 22-gauge Quinke-type spinal needles was performed with $1 \%$ lidocaine without instillation of the anesthetic into the deep soft tissue. In the first block, $0.5 \mathrm{~mL}$ of $0.5 \%$ bupivacaine without epinephrine was injected at each target level.

Every patient had to complete a self-administered pain score summary and use a telephone answering system to report the degree and duration of pain relief according to a numeric pain score (from 0 to 10) before and every 30 minutes up to 6 hours after the procedure. The response was recorded as positive if

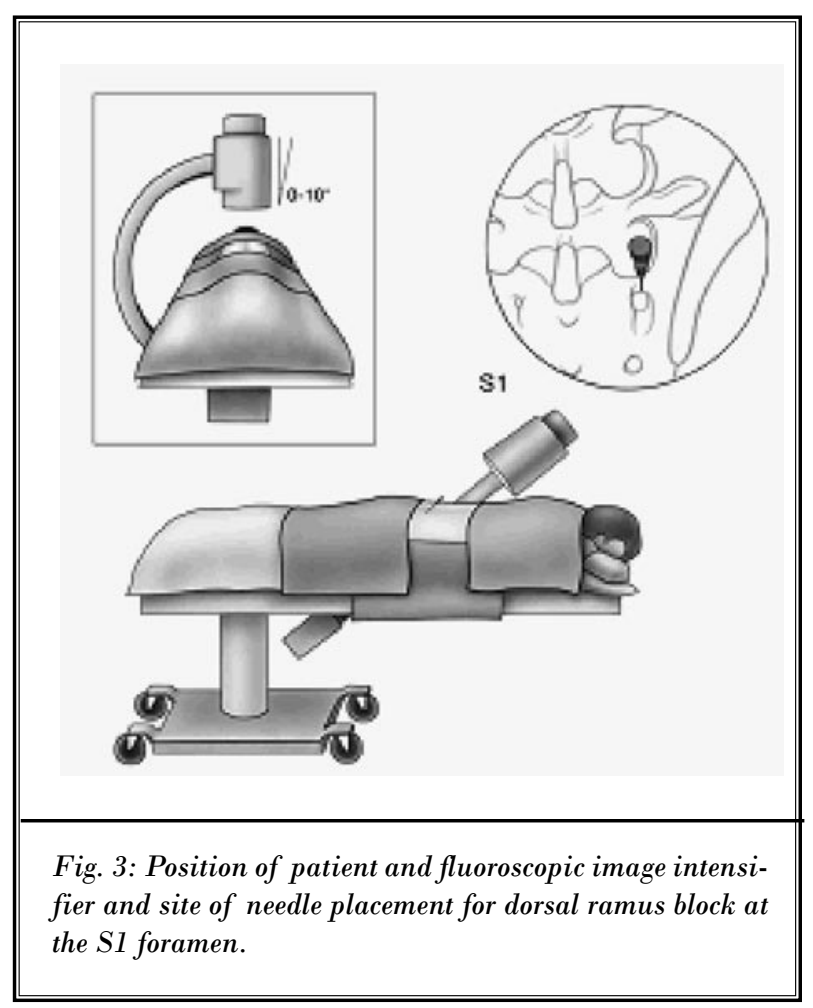


the patient experienced a decrease in numeric pain score of at least $70 \%$ for more than 3 hours.

Patients with a positive result after the first block underwent a second block on a separate occasion with $0.5 \mathrm{~mL}$ of $2 \%$ lidocaine. The same method was used to determine pain before and after the procedure. The block was considered successful if greater than $70 \%$ pain relief was obtained for more than 1 hour.

Radiofrequency facet denervation was proposed for patients who experienced pain relief (according to the stated definitions) in both diagnostic studies.

Facet denervation was performed under local analgesia and light neuroleptanesthesia accomplished by means of fentanyl and midazolam. The patient was placed in the prone position on a fluoroscopy table with a pillow under the abdomen to alleviate lumbar lordosis. The anteroposterior (AP) fluoroscopic view was obtained with maximal exposure of the target points. The skin and soft tissues were anesthetized with $1 \%$ or $2 \%$ lidocaine. The selected skin entry point was somewhat lateral to the pedicle, one level caudal for every lumbar level, excluding L5 and S1. For the L5 dorsal ramus, the entry point was approximately at the level of the $\mathbf{S 1}$ posterior foramen but less laterally than for the upper levels, so as not to superimpose the iliac crest on the sacral ala. For the S1 level, a "tunnel view" of the posterior neural foramen was obtained. The entry point was situated at the 12 o'clock position of the foramen.

From 1991 to 1997, Ray radiofrequency electrode, 16-gauge was used (Radionics, Burlington, MA) to make a single lesion. After 1997, a disposable SMK 22-gauge, 100-mm radiofrequency electrode with a 5$\mathrm{mm}$ active tip (Radionics, Minneapolis, MN) was used because of a change in institutional policy, which required use of disposable instruments. Also after 1997, the treatment consisted of 3 lesions, the first at the target site and the second and third immediately medial and lateral to the target site, to increase the burn extent.

Throughout the study period, treatment consisted of inserting the electrode and advancing it toward the target using intermittent AP fluoroscopy. Several steps were taken to ensure placement of the electrode at the correct final position at the base of the corresponding SAP. First, bone contact was made just caudal to the superior edge of the transverse process (or the sacral ala for L5), immediately lateral to the base of the SAP (Fig. 4). The oblique view was used to demonstrate correct electrode placement parallel to
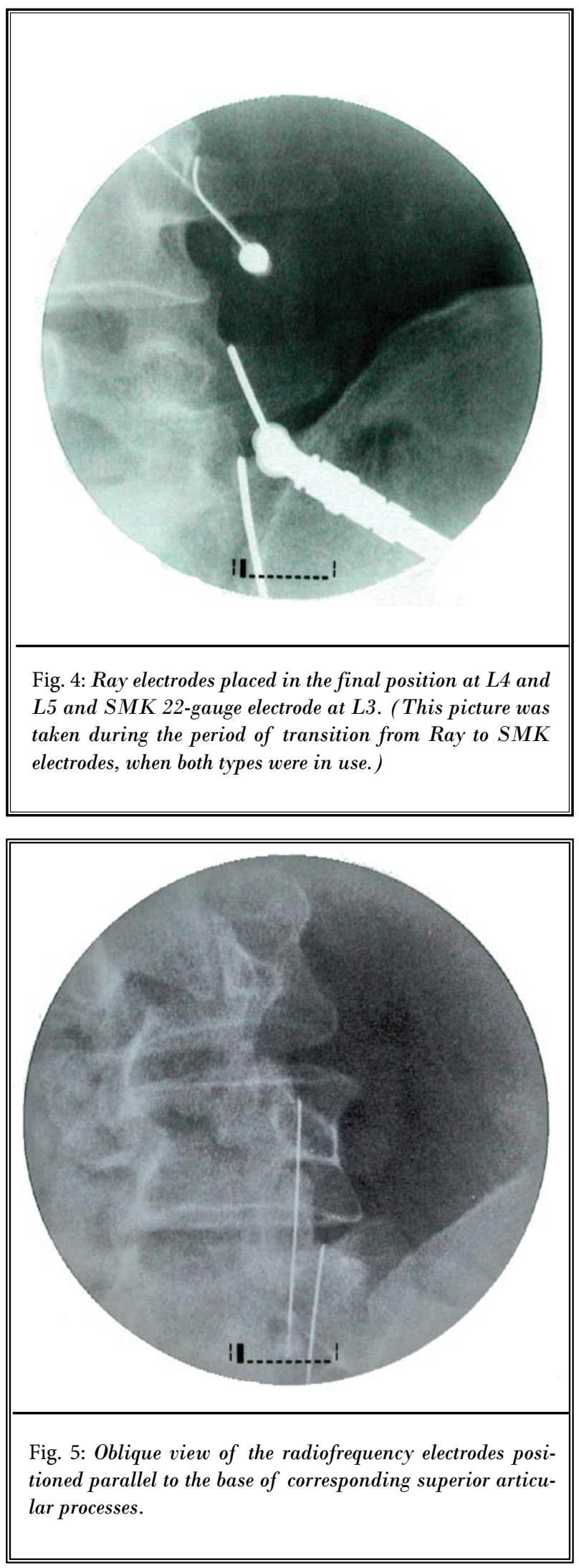
the base of the SAP (Fig. 5).

The image intensifier was then rotated to show the lateral view. The electrodes were advanced until loss of bone contact was felt and seen on fluoroscopy. Lateral views were used to ensure that the tip of the electrode did not pass the posterior boundary of the intervertebral foramen but was situated close to the anterior border of the SAP. Finally, the AP view was used to verify that the electrode still "snagged" the base of the SAP (Fig. 6).

At the S1 level, the electrode was introduced at the 12 o'clock position while constant bony contact was maintained. A lateral view was used to verify the position of the electrode outside the sacral canal (Fig. 7).

Finally, electrical stimulation at $50 \mathrm{~Hz}$ was performed for sensory testing; a dermatomal pattern was
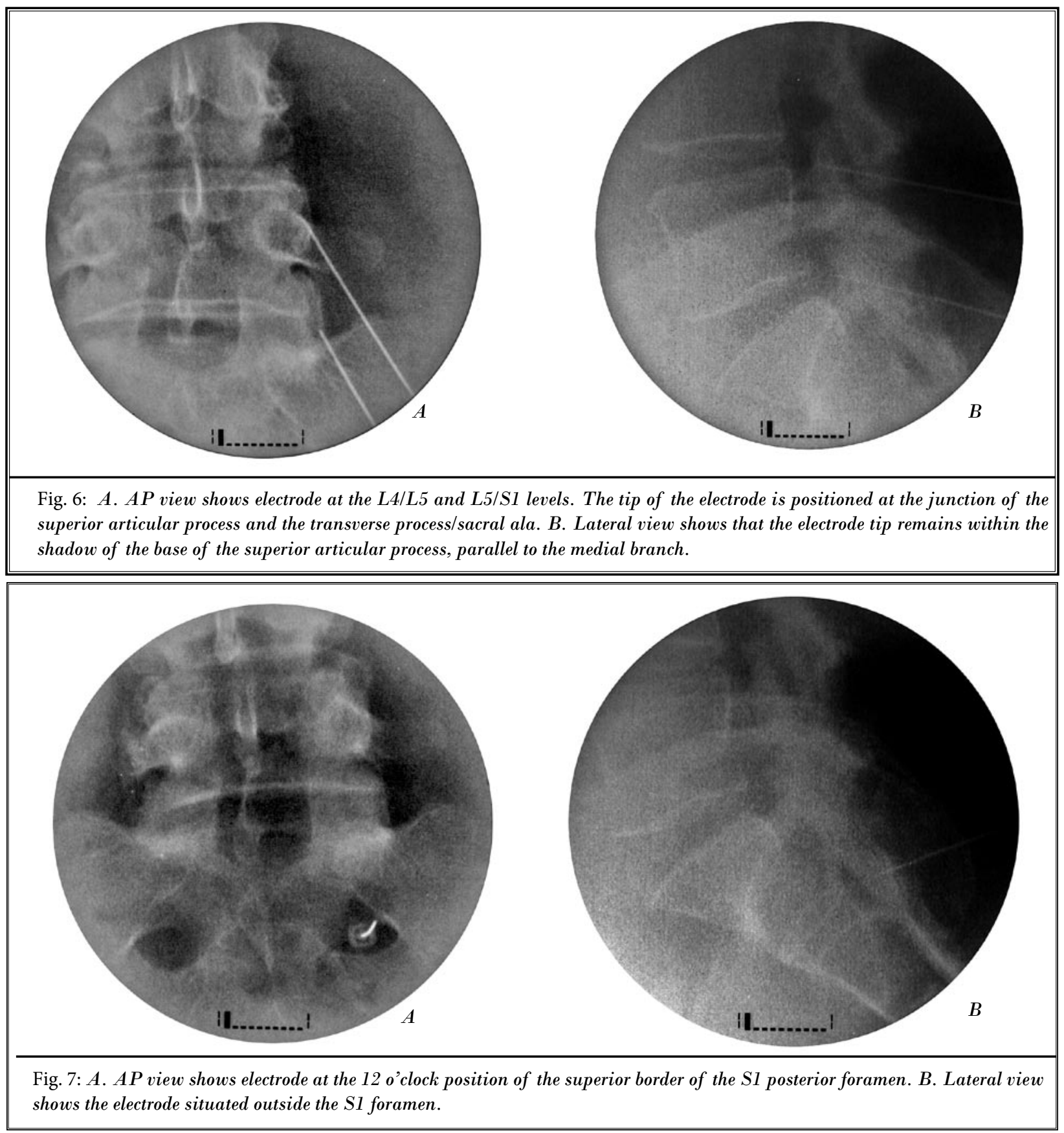
considered unacceptable. A frequency of $2 \mathrm{~Hz}$ was then applied for motor stimulation. Any motor response other than twitching of the multifidus muscles was interpreted as stimulation of the ventral ramus. In this situation, the electrode was repositioned, usually by slight withdrawal, until no dermatomal or motor response was obtained.

A small volume $(0.5-1 \mathrm{~mL})$ of local anesthetic was injected before activation of the radiofrequency generator. Three lesions were created at $80^{\circ} \mathrm{C}$ for $60 \mathrm{sec}-$ onds each.

After the procedure, ice packs were applied to decrease local reaction. Patients were advised to use analgesics for post procedural pain and to resume their usual level of physical activity as soon as possible.

At 6 weeks and at 6, 12, and 24 months after the procedure, patients completed a questionnaire in which they were asked to estimate total perceived pain reduction on a scale of $0 \%$ to $100 \%$ and to describe any change in pain medication and function (i.e., return to work, activities of daily living). Real-time pain measurement scales were not used, because, in the authors' view, they do not reflect a dynamic pattern of chronic pain. Patients returned data by mail to avoid any bias that might be associated with personal contact. The results were considered excellent, good, or poor if the patient reported greater than $80 \%$, greater than $50 \%$, or less than $50 \%$ improvement, respectively. Any degree of improvement that lasted for less than 6 months was considered to represent a treatment failure. The data were received and collated by the study's research coordinator.

Follow-up continued for 24 months or until the pain returned. A second radiofrequency procedure was offered to patients who had satisfactory relief for more than about 9 months.

\section{Results}

Over the 10-year period of the study, 209 patients were eligible for assessment, of whom 174 provided complete data and 35 were lost to follow-up or did not complete the follow-up questionnaires properly. The 174 patients with complete follow-up data consisted of 91 women (52.3\%) and 83 men (47.7\%). For $55(31.6 \%)$ of the patients, the treatment was considered a failure because they either experienced no response to the procedure or they reported pain relief lasting less than 6 months; $119(68.4 \%)$ of the patients reported good to excellent pain relief at the time of the second follow up after 6 months (Fig. 8). Out of those 119 patients, $81(96.4 \%)$ reported pain relief for 6-12 months, 36 (42.8\%) for 12-24 months, and 2 (2.4\%) for more than 24 months (Fig. 9).

Median pain relief among all eligible 174 patients

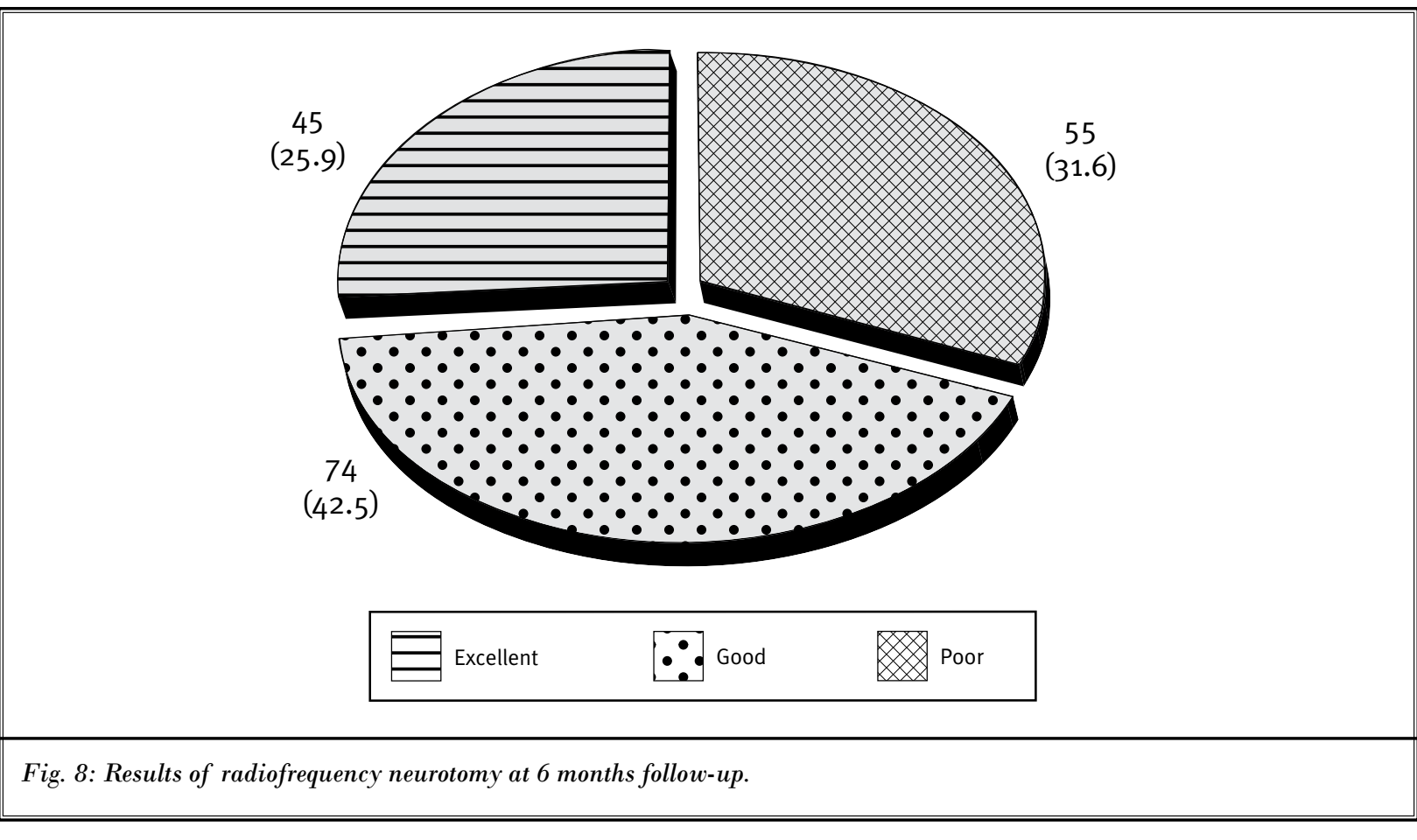




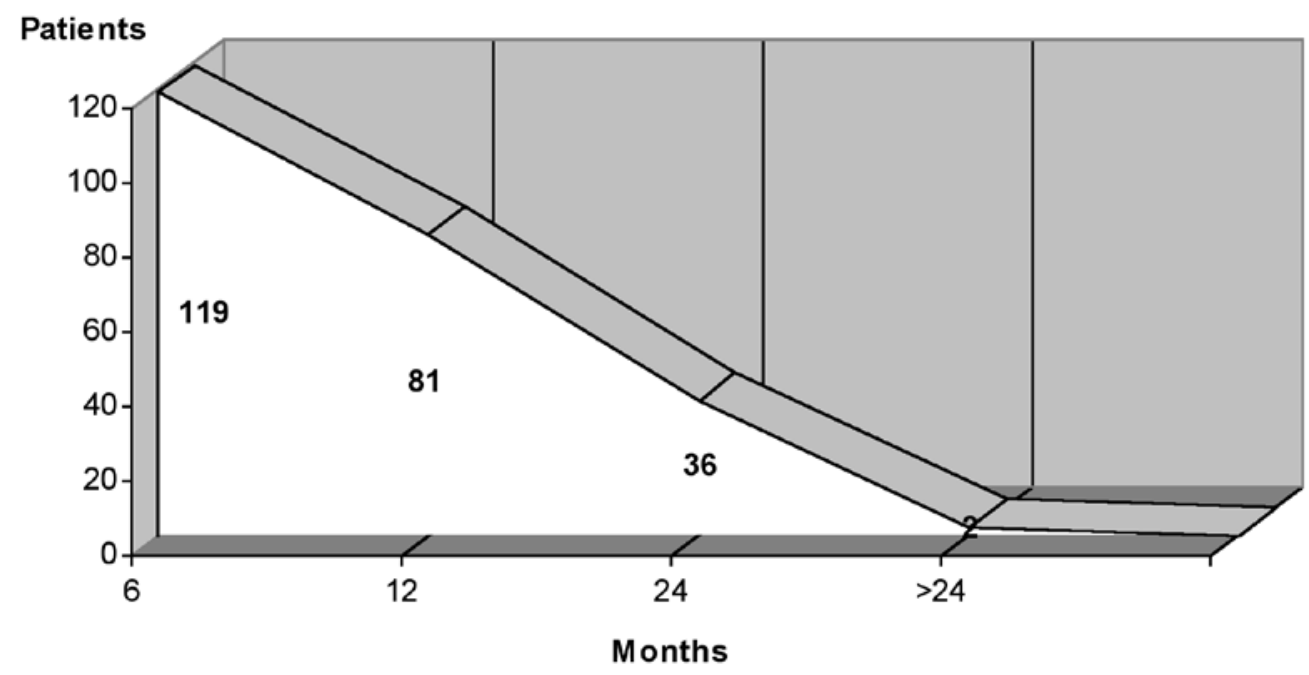

Fig. 9: Regression of initially obtained good to excellent pain relief during the follow-up period of 24 months.

was 9 months, although in 119 patients who maintained their good to excellent results for more than 6 months, median pain relief was 12 months.

All 119 of those with a positive response were able to increase their physical activities, and 99 $(83.2 \%)$ of these also decreased their consumption of analgesics according to a simple 3-points assessment score: decrease/ no change/ increase. Use of analgesics remained unchanged in the other 20 patients with a positive response.

\section{Discussion}

The results of the completed clinic audit confirmed the correctness of our routine setup of preadmission screening, and the practice of comparative diagnostic blocks with an unbiased record of the results and technique of radiofrequency procedure. We believe that radiofrequency ablation of corresponding nerves is an effective long-term tool for the management of chronic low back pain secondary to abnormalities of the lumbar facet in selected patients. The clinical audit reported here is unique for several reasons. First, it is (to the authors' knowledge) the largest collection of prospective outcome data for this procedure ever published. Second, the diagnostic approach, criteria for patient selection, performance of comparative double diagnostic blocks, technique for radiofrequency denervation, and analysis of results were standard- ized and completed by (or under the supervision of) a single operator (G.F.). Third, the primary purpose of this data was not publication, but rather development of an institutional database for quality control and analysis of the time-response relationship for the procedure.

Our selection criteria were based on the assumption that every patient with chronic, nonradicular low back pain was eligible for diagnostic blocks of the facet nerve. Imaging studies were used to exclude other problems, such as vertebral fractures, metastatic disease, overt disk herniation, and spinal stenosis, rather than to confirm anatomic degeneration or deformity of the facet joints. Even though abnormalities of the facet joint are common, previous studies have shown no correlation between imaging findings and zygapophysial joint pain (17). Therefore, comparative double diagnostic blocks remain the most powerful tool for the diagnosis of facet-mediated pain. Relative to placebo, this method has been shown to be reliable and highly specific if pain relief is nearly complete and lasts longer after a long-acting anesthetic than a short-acting local anesthetic (18). Even though the use of certain clinical criteria, known as Revel's tests, can potentially substitute for a diagnostic block or at least reduce the number of diagnostic blocks to one injection, this practice may be subject to both falsenegative and false-positive results (19). Comparative 
single-blind diagnostic blocks should provide $100 \%$ diagnostic confidence by confirming facet joint pain among nonselected or a partially selected group of patients with chronic low back pain (19). A considerable proportion of patients in our study did not experience pain relief of more than $50 \%$ after the radiofrequency procedure. Potential explanations could lie in the multifactorial nature of chronic low back pain and/or the liberal selection criteria.

Psychological assessment is believed to be of paramount importance in predicting the results of interventional pain treatment (20). Our screening questionnaire excludes patients for whom this procedure would be overtly inappropriate. It is not intended as a substitute for formal psychological assessment, which we feel is unnecessary for minimally invasive procedures such as this.

Numerous small studies of radiofrequency have been done, with widely varying but mostly positive results. The plethora of small observational studies prompted several randomized controlled trials to confirm the efficacy of the procedure, and 4 such studies have been published to date (6-9). Unfortunately, they all contained, in retrospect, methodological and technical flaws and, therefore, failed to clarify the efficacy of radiofrequency neurotomy for the treatment of zygapophysial pain. None of these studies employed comparative or placebo-controlled blocks, nor did they use an anatomically validated technique (i.e., placement of the electrode parallel to the target nerve $(5,21)$.

In previous studies, only Dreyfuss et al (12) applied strict patient selection criteria, conducted comparative double diagnostic blocks, and performed the radiofrequency procedure according to the anatomy of the target nerves. These authors also used multiple outcome tools and had a follow-up period of appropriate duration. About $60 \%$ of the patients in their study experienced at least $90 \%$ relief of pain at 12 months, and $87 \%$ experienced at least $60 \%$ relief at that time point. The only major limitation of this study was the small number of patients followed (15 patients). Nevertheless, because of this work, practitioners are now called upon to use validated and anatomically correct techniques. Dreyfuss et al (12) also remarked on the futility of preliminary electrical stimulation of the nerve to the facet, provided the electrode is accurately positioned in the groove at the base of the SAP, between the intervertebral foramen and the mamillo-accessory ligament. The main principle of lumbar facet denerva- tion is the correct placement of the electrode parallel to the target nerve (22).

At the authors' institution, this principle is applied routinely. Although there are no specific validated techniques for denervation of the S1 dorsal ramus, the contribution of this nerve to the sensory supply of the L5-S1 facet joint is well known (23). The technique of radiofrequency denervation of the $\$ 1$ dorsal ramus used in our facility was originally described by Ray (24) in 1982.

The results reported here are more modest than those of Dreyfuss et al (12), even though the postblock selection paradigm and technique of radiofrequency denervation were similar. Possible explanations include the statistical weakness of a small study such as that of Dreyfuss et al (12) (small studies typically report much higher success rates than larger, confirmatory studies) and the strict selection criteria applied before diagnostic block in that study (25). We did not use the same selection criteria feeling that overzealous patient selection would be impractical and could result in false-negative exclusions. In contrast, our inclusion criteria were based on the routine clinical practice, not ideal laboratory conditions. Nonetheless, we confirmed the efficacy of radiofrequency denervation for chronic pain control beyond a short-term follow-up.

We believe that short-term positive results do not warrant repetition of the procedure. For this reason, beneficial responses lasting less than 6 months were considered to represent treatment failures. The success rate would be substantially higher than reported here if patients with short-term relief were included. Similarly, $50 \%$ reduction in pain is a questionable benchmark, since it has been derived from pharmaceutical studies. It therefore seemed logical to use functional and quality-of-life assessments as well, given that many patients with only moderate pain reduction were generally satisfied. For practical purposes, and based on the results of the audit, we have subsequently added the Likert score of patient satisfaction, rather than using a pain reduction scale as a sole outcome measurement.

\section{Conclusions}

This large prospective clinical audit suggest that radiofrequency denervation of lumbar zygapophysial joints provides long-term pain relief. Selection should be based on preadmission screening and carefully performed comparative diagnostic blocks. 
Acknowledgments

\author{
We thank Kathleen Ross and Jenny Lam-McCulloch \\ for their assistance in collecting and analyzing the \\ data.
}

\section{References}

1. Boswell MV, Shah RV, Everett CR, Sehgal N, Brown AM, Abdi S, Bowman RC 2nd, Deer TR, Datta S, Colson JD, Spillane WF, Smith HS, Lucas LF, Burton AW, Chopra P, Staats PS, Wasserman RA, Manchikanti $\mathrm{L}$. Interventional techniques in the management of chronic spinal pain: evidence-based practice guidelines. Pain Physician 2005; 8:1-47.

2. Sehgal N, Shah RV, McKenzie-Brown A, Everett CR. Diagnostic utility of facet (zygapophysial) joint injections in chronic spinal pain: A systematic review of evidence. Pain Physician 2005; 8:211-224.

3. Ghormley RK. Low back pain with special reference to the articular facet, with presentation of operative procedure. JAMA 1933; 101:1773-1777.

4. Shealy CN. Percutaneous radiofrequency denervation of the lumbar facets. J Neurosurg 1975; 43:448-451.

5. Bogduk N, Long DM. The anatomy of the so-called "articular nerves" and their relationship to facet denervation in the treatment of low back pain. J Neurosurg 1979; 51:172-177.

6. van Kleef M, Barendse GA, Kessels A, Voets HM, Weber WE, de Lange S. Randomized trial of radiofrequency lumbar facet denervation for chronic low back pain. Spine 1999; 24:1937-1942.

7. Gallagher J, Petriccione Di Vadi PL, Wedley JR, Hammann W, Ryan P, Chikanza I, Kirham B, Price R, Watson MS, Grahame R, Wood S. Radiofrequency facet joint denervation in the treatment of low back pain: a prospective controlled double-blind study to assess its efficacy. Pain Clin 1994; 7:193-198.

8. Leclaire R, Fortin L, Lambert R, Bergeron
YM, Rossignol M. Radiofrequency facet joint denervation in the treatment of low back pain: a placebo-controlled clinical trial to assess efficacy. Spine 2001; 26:1411-1416.

9. van Wijk RM, Geurts JW, Wynne HJ, Hammink E, Buskens E, Lousberg R, Knape JT, Groen GJ. Radiofrequency denervation of lumbar facet joints in the treatment of chronic low back pain: a randomized, double-blind, sham lesion-controlled trial. Clin J Pain 2005; 21:335-344.

10. Bogduk N, Macintosh J, Marsland A. Technical limitations to the efficacy of radiofrequency neurotomy for spinal pain. Neurosurgery 1987; 20:529-535

11. Lau P, Mercer S, Govind J, Bogduk N. The surgical anatomy of lumbar medial branch neurotomy (facet denervation). Pain Med 2004; 5:289-298.

12. Dreyfuss P, Halbrook B, Pauza K, Joshi A, McLarty J, Bogduk N. Efficacy and validity of radiofrequency neurotomy for chronic lumbar zygapophysial joint pain. Spine 2000; 25:1270-1277.

13. National Institute for Clinical Excellence. Principles for best practice in clinical audit. Radcliffe Medical Press Ltd, Oxon, UK: 2002.

14. Barnsley L. Percutaneous radiofrequency neurotomy for chronic neck pain: outcomes in a series of consecutive patients. Pain Med 2005; 6:282-286.

15. Cleeland CS. Brief pain inventory. In: Turk DC, Melzack R (eds). Handbook of pain assessment. New York, 1992, pp 367-370.

16. Melzack R. The McGill Pain Questionnaire: major properties and scoring methods. Pain 1975; 1:277-299.
17. Schwarzer AC, Wang SC, O'Driscoll D, Harrington T, Bogduk N, Laurent R. The ability of computed tomography to identify a painful zygapophysial joint in patients with chronic low back pain. Spine 1995; 20:907-912.

18. Lord SM, Barnsley L, Bogduk N. The utility of comparative local anesthetic blocks versus placebo-controlled blocks for the diagnosis of cervical zygapophysial joint pain. Clin J Pain 1995; 11:208-213.

19. Bogduk N. Diagnosing lumbar zygapophysial joint pain. Pain Med 2005; 6:139-142.

20. Hinnant DW, Tollison CD. Psychological evaluation of the patient in pain. In Waldman SD (ed). Interventional Pain Management. 2nd ed. W.B. Saunders Company, Philadelphia, PA, 2001, pp 191-200.

21. Bogduk N, Long D. Percutaneous lumbar medial branch neurotomy: a modification of facet denervation. Spine 1980; 5:193-200.

22. Bogduk N, Macintosh J, Marsland A. Technical limitations to the efficacy of radiofrequency neurotomy for spinal pain. Neurosurgery 1987; 20:529-35.

23. Paris $S$. Anatomy as related to function and pain. Orthop Clin North Am 1983; 14:475-489.

24. Ray CD. Percutaneous radio-frequency facet nerve blocks: treatment of mechanical low back pain. In Radionics $\mathbb{B}$ procedure technique series. Burlington, MA: Radionics; 1982.

25. Ioannidis JP. Contradicted and initially stronger effects in highly cited clinical research. JAMA 2005; 294:218-228. 
